\title{
Knowledge, Attitude and Practice of Personal Safety Measures Adopted by Medical Practioners during the Covid-19 Pandemic
}

\author{
Hemapriya L. ${ }^{1}$, Maureen Prativa Tigga ${ }^{2}$, Anil Kumar M.R ${ }^{3}$, Prathap Tㄴ, Neha Wali ${ }^{5}$, Shreya Chandran ${ }^{6}$ \\ 1, 2, 4, 5 Department of OBG, JSS Medical College \& Hospital, JSS AHER, Mysore, Karnataka, India. \\ ${ }^{3}$ Department of Anaesthesiology, JSS Medical College \& Hospital, JSS AHER, Mysore, Karnataka, India. \\ ${ }^{6}$ JSS Medical College \& Hospital, JSS AHER, Mysore, Karnataka, India.
}

\section{ABSTRACT}

\section{BACKGROUND}

A novel coronavirus (now termed as SARS-CoV-2) was detected as the causative agent of severe pneumonia in Wuhan, Hubei Province, China, in December 2019. Declared by the World Health Organization (WHO) as a global pandemic in March 2020, it has created profound changes in global economy and healthcare systems. This study evaluates the knowledge and practice with regard to various personal safety measures used by the healthcare professionals.

\section{METHODS}

We conducted a questionnaire study after obtaining approval, from the Institutional ethical committee. An online survey was conducted using a preformatted questionnaire consisting of multiple-choice questions which assessed the knowledge and practices adopted by various healthcare professionals. The survey was done between 1st and 30th of June 2020 and a total of 536 responses was analysed.

\section{RESULTS}

$58.4 \%$ of the participants were females, $66 \%$ of the healthcare workers worked at a private hospital / private medical college with $82.1 \%$ being located in urban areas. Of the 536 respondents, $90.1 \%$ practiced bathing immediately after returning home and $86.8 \%$ sanitized their accessories. $86.9 \%$ of the professionals used frequent sanitization with use of mask and gloves whereas only $12.3 \%$ used full personal protective equipment. $58 \%$ of females had used hydroxychloroquine as prophylaxis whereas only $41 \%$ of males used it (statistically significant, $P=0.005$ ). Healthcare workers in younger age group (23 - 40 years) were more likely to maintain distance with family members, and government doctors were significantly more likely to do so $(\mathrm{P}<0.001)$ as compared to private practitioners.

\section{CONCLUSIONS}

With the medical professionals being at high risk for contracting the infection, the need to provide the healthcare professionals with adequate personal protective equipment is of utmost importance. There is also a need to maintain the well-being of the healthcare professionals as they are the weakest link in the chain.

\section{KEY WORDS}

Medical Practitioners, Personal Protective Equipment, Safety Measures
Corresponding Author: Dr. Hemapriya $L$.

No. 73, 1st stage, 8th cross, Gokulam, Mysore - 570002, Karnataka, India. E-mail: drpriya_911@hotmail.com

DOI: $10.14260 / j e m d s / 2021 / 190$

How to Cite This Article:

Hemapriya L, Tigga MP, Kumar MR, et al. Knowledge, attitude and practice of personal safety measures adopted by medical practioners during the covid-19 pandemic. J Evolution Med Dent Sci 2021;10(12):883-887, DOI: 10.14260/jemds/2021/190

Submission 18-11-2020,

Peer Review 23-01-2021,

Acceptance 02-02-2021,

Published 22-03-2021.

Copyright (c) 2021 Hemapriya L. et al. This is an open access article distributed under Creative Commons Attribution License [Attribution 4.0 International (CC BY 4.0)] 


\section{BACKGROUND}

In December 2019, a set of patients in the city of Wuhan, Hubei Provence, China presented with severe pneumonia of unknown origin. Epidemiologically these were linked to a seafood market in the city. On January 7, 2020 the causative organism was identified to be a novel coronavirus now termed SARS-CoV-2. ${ }^{1}$ In March 2020 the World Health Organization declared it a global pandemic. ${ }^{2}$

It is seen that during the outbreak of any new infectious disease, there are many unknown factors such as mode of disease transmission, risk factors, preventive measures and management options. ${ }^{3}$ There are various myths and rumours which increase the sense of panic not only among the lay people, but also among professionals. The spread of the novel coronavirus has created a similar situation because we are ill equipped, in terms of knowledge, supplies, infrastructure, and most important, not mentally prepared to deal with this crisis. The outbreak of this novel coronavirus has fundamentally changed the world and is rapidly changing the attitude of medical practitioners. The health workers have now switched to the norm of personal safety first followed by patient safety. This pandemic has also brought about huge changes in global economy and healthcare systems. ${ }^{4}$

In order to prevent transmission of disease from hospitals to the community, and to ensure smooth functioning of the health care system, it has become mandatory to ensure the safety of health care workers, who are at high risk due to close contact with patients. A similar situation was seen during the SARS-CoV-1 epidemic, where doctors and other health workers were highly infected, due to inadequate personal protection. ${ }^{5}$

The Covid-19 virus is transmitted either through close contact with an infected patient or by droplet spread. ${ }^{4}$ Hence, people who care for the infected patients are at the highest risk of getting affected. By the start of April 2020, over one million people had been confirmed.

Infected with SARS-CoV-2. Various guidelines have been enforced for the protection of health workers, including social distancing, hand hygiene, N95 masks, goggles, gloves, gowns, face shields, cover all's, precautions for aerosol generating procedures and frequent sanitization. The current guidelines from the World Health Organization regarding the use of various levels of personal protective equipment are based on the assumption that transmission occurs through droplets, either direct or indirect. ${ }^{6}$ Direct droplet spread occurs when respiratory particles greater than 5 microns in diameter are in contact with the mucosal surface of a recipient.

Indirect spread is said to occur when a fomite or an intermediate surface is touched by hand, and then contacts the mucosa

Health care professionals should be educated on when to use which personal protective equipment (PPE), how to put on \& take off, how to change them by themselves to prevent contamination and how to properly disinfect and discard this equipment. Health care institutions should have procedures and policies that describe the correct order of donning and doffing PPE in a safe manner. ${ }^{7}$

This study evaluates the knowledge and practice of the various personal safety measures used by medical practitioners to protect themselves from exposure to this pandemic.

\section{METHODS}

We conducted an online questionnaire survey regarding the knowledge and practice of personal safety measures used by medical practitioners during the Covid-19 pandemic. The institutional ethical committee approval was obtained. The survey was done between 1st - 30th of June 2020 and a total of 536 responses were analysed. We collected data using a preformatted questionnaire sent through e-mail or Google form and recorded all responses. The survey consisted of questions, with the help of which we assessed the knowledge of medical practitioners, and the various measures and practices adopted by them for their personal safety during the Covid-19pandemic. All medical practitioners who agreed to participate in the study from the first to the thirtieth of June 2020 were enrolled in the study. We obtained 576 responses. The questionnaire was given as a pilot on 10 subjects to make sure that it was easy to understand and not time consuming. Based on the feedback obtained, it required no changes. The average time to complete the survey during the pilot was five minutes. The piloted subjects and the subjects who did not complete the questionnaire were excluded and the final number included for analysis was 536 .

\section{Statistical Analysis}

The data was compiled and analysed using MS Excel and SPSS software version 25 at $5 \%$ level of significance. The tools of statistics such as - descriptive statistics, chi-square test, some parametric / non-parametric tests were used for data analysis.

\section{RESULTS}

The demographic characteristics of our respondents are tabulated below.

\begin{tabular}{|c|c|c|c|}
\hline & Age & Number & Percentage \\
\hline & $23-30$ & 157 & 29.3 \\
\hline & $30-40$ & 172 & 32.1 \\
\hline & $40-50$ & 128 & 23.8 \\
\hline & $50-60$ & 54 & 10.1 \\
\hline & Above 60 & 25 & 4.7 \\
\hline \multirow{2}{*}{ Sex } & Male & 223 & 41.6 \\
\hline & Female & 313 & 58.4 \\
\hline \multirow{3}{*}{ Family size } & 1 to 4 members & 317 & 59.1 \\
\hline & 5 to 8 members & 206 & 38.4 \\
\hline & 9 members and above & 13 & 2.4 \\
\hline \multirow{3}{*}{ Place of work } & Clinic & 44 & 8.2 \\
\hline & $\begin{array}{l}\text { Government hospital / } \\
\text { government medical college }\end{array}$ & 138 & 25.7 \\
\hline & $\begin{array}{l}\text { Private hospital / private } \\
\text { medical college }\end{array}$ & 354 & 66.0 \\
\hline \multirow{3}{*}{ Area of work } & Rural & 27 & 5.0 \\
\hline & Semi urban / rural & 69 & 12.9 \\
\hline & Urban & 440 & 82.1 \\
\hline \multirow{4}{*}{ Department } & Anaesthesia & 43 & 8.0 \\
\hline & Laboratory medicine & 17 & 3.2 \\
\hline & Medical specialty & 192 & 35.8 \\
\hline & Surgical specialty & 284 & 53.0 \\
\hline \multirow{3}{*}{ Designation } & Consultant & 379 & 70.7 \\
\hline & Intern & 42 & 7.8 \\
\hline & Postgraduate & 115 & 21.5 \\
\hline \multirow{5}{*}{ Experience group } & 0 to 10 years & 253 & 47.2 \\
\hline & 10 to 20 years & 162 & 30.2 \\
\hline & 20 to 30 years & 82 & 15.3 \\
\hline & 30 to 40 years & 32 & 6.0 \\
\hline & 40 years and above & 7 & 1.3 \\
\hline \multicolumn{4}{|c|}{ Table 1. Demographic Characteristics } \\
\hline
\end{tabular}


Fifty two percent of our respondents reported to have had encountered suspected Covid 19 patients. However, only 12.9 $\%$ were quarantined following such exposure. Five percent of the practitioners were forced to move out of their homes following suspected exposure, in order to minimise risk to their family members.

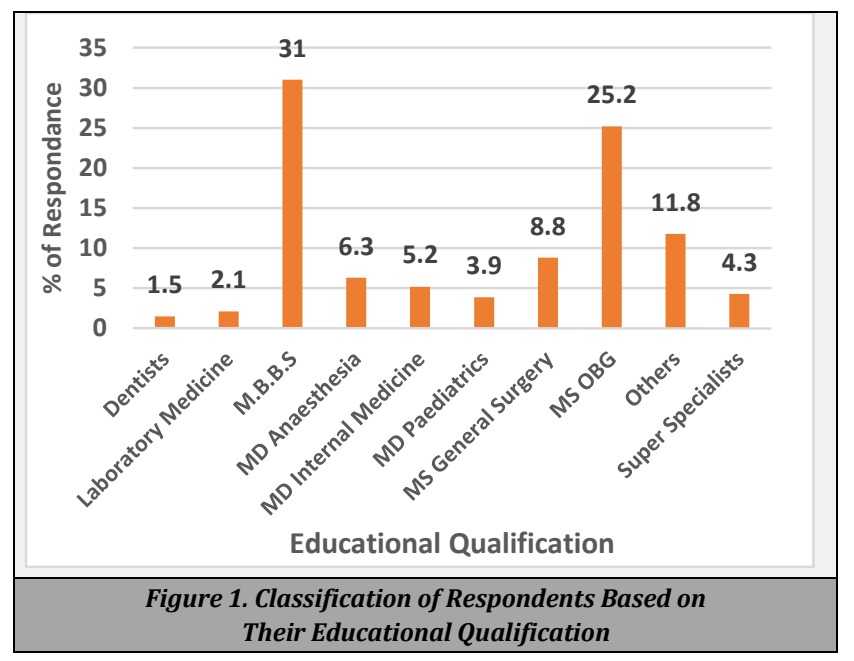

\begin{tabular}{|c|c|c|}
\hline $\begin{array}{c}\text { Precautionary Measure Taken Before } \\
\text { Consulting any Patient }\end{array}$ & Frequency & Percent \\
\hline Sanitizing and full PPE & 66 & 12.3 \\
\hline Sanitizing, mask and glove & 466 & da86.9 \\
\hline $\begin{array}{l}\text { Placing a mask / sanitizer outside the door for } \\
\text { use by hospital staff and visitor }\end{array}$ & 408 & 76.1 \\
\hline Taken hydroxychloroquine prophylaxis & 199 & 37.1 \\
\hline $\begin{array}{l}\text { Taken any online consultation / class because of } \\
\text { Covid-19 }\end{array}$ & 164 & 30.6 \\
\hline Bathe immediately reaching home & 483 & 90.1 \\
\hline $\begin{array}{c}\text { Sanitize the accessories immediately reaching } \\
\text { home }\end{array}$ & 465 & 86.8 \\
\hline $\begin{array}{l}\text { Maintain distance with family members when at } \\
\text { home }\end{array}$ & 251 & 46.8 \\
\hline $\begin{array}{l}\text { Advised / administered hydroxychloroquine } \\
\text { prophylaxis to family }\end{array}$ & 128 & 23.9 \\
\hline
\end{tabular}

Out of the 536 subjects, $86.9 \%$ were using sanitization, mask and glove, while only $12.3 \%$ were using full PPE as a precautionary measure during their working hours. Among the respondents who used full PPE along with sanitization, $43.9 \%$ were from the surgical specialty, $39.4 \%$ from medical specialty, $10.6 \%$ were anaesthetists and $6.06 \%$ belonged to laboratory medicine. Almost half the subjects (50.4\%) reported interference of PPE in the quality of work sometimes. Twenty seven percent of the subjects felt the interference of PPE with work frequently. Other forms of protection such as physical barriers were not widely used at the time of our data collection. There was no significant difference between male and female practitioners regarding the various personal safety measures. Similarly, on comparing the various age groups, designation of practitioners, place of work and area of work; we found no significant difference in the use of personal safety measures. However, on comparing the different specialties, we found that dentists were significantly more inclined to use full PPE in their practice as compared to others (P value $<0.0001$ ). Female practitioners were more likely to place sanitizers, masks at the entrance of their consulting rooms, as a measure for their own safety, although not statistically significant.

Regarding the use of hydroxychloroquine prophylaxis, 58 $\%$ of females had used it as compared to $41 \%$ of males, which is statistically significant $(\mathrm{P}=0.005)$. Practitioners in the age group of 23 - 30 and 30 - 40 years were significantly more likely to have taken hydroxychloroquine than older practitioners. However, those in older age group had administered prophylaxis more often to their family members, as compared to younger doctors. Similarly, physicians and general surgeons reported to have taken hydroxychloroquine along with their families significantly more than other specialists.

Those in the younger age group, between $23-40$ years were more likely to maintain distance with their family members, especially physicians and paediatricians. Government doctors were significantly more likely to do so ( $P$ $<0.001$ ) as compared to private practitioners. Incidence of exposure and post exposure measures were not part of our study. None of our respondents reported to have been infected by the SARS-CoV-2 virus, hence, post infection measures could not be evaluated. Further studies are required to evaluate the rates of infection of health workers in relation to the type of protective equipment they use.

\section{DISCUSSION}

The coronavirus disease 2019 (Covid-19) has become an international health crisis, and the global health care system was ill equipped to handle a crisis of such magnitude. The safety of healthcare workers has become the top priority, in order to prevent collapse of healthcare systems and also to prevent transmission of infection from health workers to the community. Medical practitioners are at the highest risk of infection because of frequent close contact with patients who are known or suspected to be infected. A similar situation was seen during the previous SARS-CoV-1 epidemic, where $20 \%$ of the cases comprised of health care workers. ${ }^{8}$

Worldwide, over one million people were confirmed to be infected with SARS-CoV-2 by April 2020. Assuming that healthcare workers were infected at the same rate as in the SARS-CoV-1 epidemic, it would foretell the collapse of health care system, especially in developing countries. ${ }^{9}$

\begin{tabular}{|c|c|c|c|c|c|c|c|c|}
\hline Specialty & Masks Only & Gloves Only & $\begin{array}{l}\text { Mask + Face } \\
\text { Shield }\end{array}$ & Mask + Gloves & $\begin{array}{l}\text { Mask + Gloves + } \\
\text { Face Shield }\end{array}$ & $\begin{array}{c}\text { Mask + Gloves + } \\
\text { Goggles }\end{array}$ & $\begin{array}{c}\text { Mask + Gloves + } \\
\text { Face Shield + PPE } \\
\text { Suit }\end{array}$ & Total \\
\hline Surgical & 0 & 0 & 0 & 156 (61.9\%) & 20 (7.9\%) & 56 (22.2 \%) & 20 (7.9\%) & 252 \\
\hline Medical & 0 & 0 & 0 & 130 (78.8 \%) & 18 (10.9\%) & 05 (3.03 \%) & 12 (7.27 \%) & 165 \\
\hline Anaesthesia & 0 & 0 & 0 & 20 (55.5\%) & 10 (15.8\%) & 05 (13.8 \%) & $1(27.7 \%)$ & 36 \\
\hline Lab medicine & 0 & 0 & 0 & 08 (61.5 \%) & $5(38.4 \%)$ & $0(0)$ & $0(0)$ & 13 \\
\hline \multirow{2}{*}{ Dental } & 0 & 0 & 0 & 05 (7.14 \%) & $45(64.28 \%)$ & 15 (21.4\%) & 05 (7.14 \%) & 70 \\
\hline & & & & & & & & 536 \\
\hline
\end{tabular}


There has always been an acceptance that working in a healthcare setting carries a level of personal risk, however, it would seem unreasonable for a healthcare worker to carry out a healthcare activity if there was a high risk of death. ${ }^{8}$ Hence the need for personal protection of frontline warriors is of utmost importance to provide unconditional healthcare services.

Earlier in the pandemic, infection of healthcare workers was as high as $29 \%$, and this dramatically decreased thereafter due to PPE measures put in place to appropriately protect healthcare workers. ${ }^{10}$ Current personal protective equipment (PPE) and infection control guidelines from the World Health Organization are based on the assumption that the primary mechanism of transmission is direct and indirect droplet spread. ${ }^{11}$

In the current crisis, health-care workers not only have to work harder and longer hours, they often do so in a context where the knowledge and understanding of the novel pathogen is still suboptimal. More than $50 \%$ of the subjects in the current study reported interference of PPE in their quality of work. The use of PPE also interferes with vision, difficulty in operating or carrying out procedures. It not only hampers movement and interferes with skills, also, the regular donning and doffing of full PPE add to physical fatigue and psychological stress.

Aerosol generating procedures may lead to an increase in transmission rates among practitioners. However, the evidence is limited. Infections of health workers following the performance of aerosol generating procedures have been reported, but the exact timing and cause of transmission is unknown. ${ }^{12}$ The risk is observed not only during the procedure, but during all periods of contact with the infected patient. Therefore, precautions, and proper PPE usage should be followed not only during procedural periods alone but increase this protection to all times of risk. ${ }^{13}$

While awaiting a vaccine, hygiene measures, social distancing and personal protective equipment are the only primary prophylaxis measures against SARS-CoV-2, but they have not been sufficient to protect our healthcare professionals. ${ }^{14}$ Some evidence of the in vitro efficacy of hydroxychloroquine against this virus is known, along with some clinical data that would support the study of this drug in the chemoprophylaxis of infection. However, there are still no data from controlled clinical trials in this regard.

In the aftermath of the current pandemic, the exact mode of transmission may still remain controversial as was the case with SARS-CoV-1 and influenza. Urgent further research is required to investigate SARS-CoV-2 transmission, risk factors and strategies to assure the safety of healthcare workers. In the interim, healthcare workers may choose to take a precautionary approach until robust evidence is available.

\section{CONCLUSIONS}

The medical work force is at high risk of exposure as well as increased viral load and although there is a need to balance limited supplies with staff and patient safety, this should not leave the healthcare professionals treating patients with inadequate PPE. Along with extrinsic organisational, infrastructural and procedural conditions, the intrinsic state and well-being of the health-care worker must also be addressed in order for him or her not to be the weakest link.

Personal protection of frontline workers to provide unconditional healthcare services is of utmost importance in the current era as loss of even 1 doctor equals loss of services of almost 1000 patients.

Data sharing statement provided by the authors is available with the full text of this article at jemds.com.

Financial or other competing interests: None.

Disclosure forms provided by the authors are available with the full text of this article at jemds.com.

\section{REFERENCES}

[1] Andersen KG, Rambaut A, Lipkin WI, et al. The proximal origin of SARS-CoV-2. Nat Med 2020;26(4):450-2.

[2] Sohrabi C, Alsafi Z, O'Neill N, et al. World Health Organization declares global emergency: a review of the 2019 novel coronavirus (Covid-19). Int J Surg 2020;76:71-6.

[3] Schuchat A, Bell BP, Redd SC. The science behind preparing and responding to pandemic influenza: the lessons and limits of science. Clin Infect Dis 2011;52(Suppl 1):S8-S12.

[4] Wax RS, Christian MD. Practical recommendations for critical care and anesthesiology teams caring for novel coronavirus (2019-nCoV) patients. Can J Anesth 2020;67(5):568-76.

[5] Christian MD, Loutfy M, McDonald LC, et al. Possible SARS coronavirus transmission during cardiopulmonary resuscitation. Emerg Infect Dis 2004;10(2):287-93.

[6] World Health Organisation. Modes of transmission of virus causing Covid-19: implications for IPC precaution recommendations. 2020. https://www.who.int/newsroom/commentaries/detail/modes-of-transmission-ofvirus-causing-covid-19-implications-for-ipc-precautionrecommendations (accessed 08/04/2020).

[7] World Health Organization. www.who.int/emergencies/diseases/novel-coronavirus2019/events-as-they-happen (accessed on 4 April 2020).

[8] CDC. Interim infection prevention and control recommendations for patients with suspected or confirmed coronavirus disease 2019 (Covid-19) in healthcare settings. Atlanta, Georgia, USA: Centers for Diseases Control and Prevention 2020.

[9] Fowler RA, Guest CB, Lapinsky SE, et al. Transmission of severe acute respiratory syndrome during intubation and mechanical ventilation. Am J Respir Crit Care Med 2004;169(11):1198-202.

[10] Bloomberg RT. Why surgeons don't want to operate right now? Bloomberg 2020. https://www.bloomberg.com/opinion/articles/202003-24/thecoronavirus-crisis-is-putting-surgeons-at-risktoo

[11] Wu Z, McGoogan JM. Characteristics of and important lessons from the Coronavirus Disease 2019 (Covid-19) outbreak in China: summary of a report of 72,314 cases from the Chinese Center for Disease Control and Prevention. JAMA 2020;323(13):1239-42. 
[12] Gan WH, Lim JW, Koh D. Preventing intra-hospital infection and transmission of coronavirus disease 2019 in health-care workers. Saf Health Work 2020;11(2):241-3.

[13] Bahl P, Doolan C, de Silva C, et al. Airborne or droplet precautions for health workers treating Covid-19? J Infect Dis 2020:jiaa189.
[14] Lammers MJW, Lea J, Westerberg BD. Guidance for otolaryngology health care workers performing aerosol generating medical procedures during the Covid19pandemic. Journal of Otolaryngology-Head and Neck Surgery 2020;49(1):36. 